\title{
Estimation of Coastal Stability Due to Coastal Structures
}

\author{
Huseyin Murat Cekirge \\ Department of Mechanical Engineering, the Grove School of Engineering, the City College of the City University of New York, New York, \\ USA
}

\section{Email address: \\ hmcekirge@usa.net}

\section{To cite this article:}

Huseyin Murat Cekirge. Estimation of Coastal Stability Due to Coastal Structures.International Journal of Environmental Monitoring and Analysis.Special Issue: Environmental Social Impact Assessment (ESIA) and Risk Assessment of Crude Oil and Gas Pipelines.

Vol. 3, No. 6-1, 2015, pp. 47-55.doi: 10.11648/j.ijema.s.2015030601.16

\begin{abstract}
The coastal structures are unavoidable for various industrial operations. These are changing hydrodynamics of the marine and its adjacent areas; and are directly influencing environmental conditions of the marine environment. The sedimentation on shorelines is strongly under influence of the new structures. The methodology, which is introduced in the paper, is a comparative study of situation of sediments before and after constructing the coastal installations. It is a guiding tool for planners to find the influences of the new structures in the marine area.
\end{abstract}

Keywords: Coastal Stability, Erosion of Sediments on Coastal Shores, Deposition of Sediments on Coastal Shores, Marine Sediment Model

\section{Introduction}

This paper addresses concerns about the potential effects of a new coastal structure on coastal stability of the adjacent marine area. There are always environmental concerns about the impact of the new coastal structures on coastal areas. The monitoring agencies always consider the ecological consequences of accelerated shallowing resulting from alterations in sediment transport dynamics following the construction of the new coastal structure. The ESIA reports are always wondering the effects of coastal structures which will be constructed in marine areas. It is expected that the new structure affects hydrodynamics of the coast and it may cause of change of coastal line due to erosion and sedimentation. It is necessary to analyze effects of the coastal structure on present hydrodynamics and forecast the potential changes of coastal line using suitable hydrodynamic simulation model. Countermeasures against the impacts should be provided in accordance with the simulation results taking into consideration of environmental protection.

Geo-morphological changes focuses on observations of coastal sedimentation and the need to determine the potential changes in sediment transport, after the new coastal structure is built. The hypothesis of limited long-shore transport is consistent with the minimal sand build up at the existing coastal structure. The potential impacts due to the new coastal structure are:
- changes in wave patterns;

- changes in currents;

- changes in sediment transport;

- changes in coastal orientation; and

- secondary impacts on coastal dunes.

As a result, the building party committed to carrying out a study to further investigate the effects of the new coastal structure development on the existing hydrodynamic conditions, alongshore littoral transport rates, and offshore (sub-littoral) sediment transport patterns. The paper is addressed herein in the following:

Determining the potential effects of the solid-core coastal structure on the area's coastal stability and focusing on potential changes to the erosional/depositional condition of the shoreline.

This process entails field study and wave refraction modeling. An area, Figure 1 and 2, with metrological, wave conditions and sea bottom topography (bathymetry) are selected. 


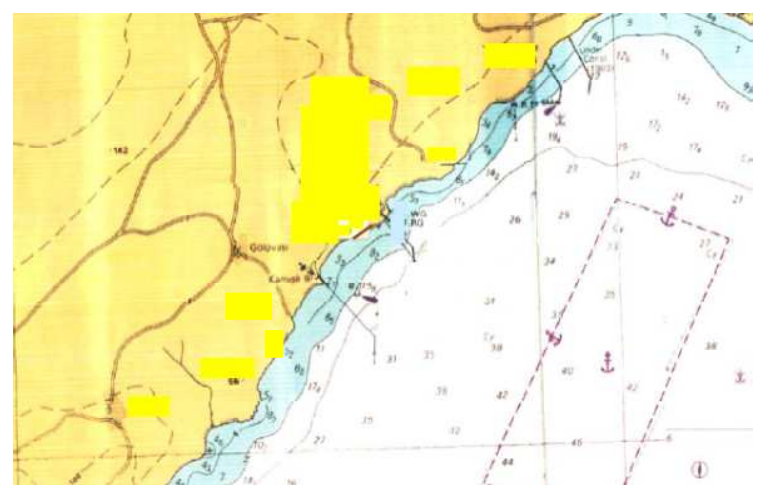

Figure 1. Location of the new coastal structure at marine area, [1].

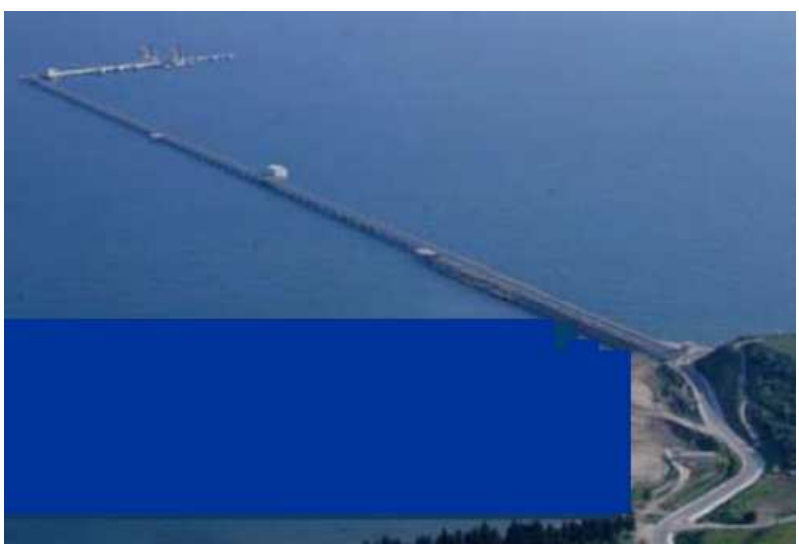

Figure 2. A typical coastal structure, a jetty, [1]

\section{Potential Changes in Sediment Transport}

A 1D (one-dimensional) vertically averaged wave refraction and sediment transport model; SEDTRANS; [1], was used to analyse changes in sedimentary transport associated with the new coastal structure. The model, among other factors, provides offshore wave height and wavelength, inshore wave heights, directions and frequencies at a series of points along the coastline. Alongshore transport rates are established and compared before and after coastal structure construction, and to determine probable changes in sediment transport and coastal erosion / deposition with respect to the shoreline types present.

\subsection{Wind Conditions}

Winds generate the waves that affect the shoreline. The wind rose for the marine area south of the marine area is presented in Figure 3. Table 1 presents a summary of wind direction by percentage.

Table 1. Annual Wind Direction-Percentage, [1].

\begin{tabular}{|llllllll|}
\hline $\mathbf{N}$ & NNE & NE & ENE & E & ESE & SE & SSE \\
\hline 14 & 16 & 1 & 2 & 1 & 5 & 1 & 6 \\
\hline & & & & & & & \\
\hline S & SSW & SW & WSW & W & WNW & NW & NNW \\
\hline 2 & 20 & 3 & 7 & 2 & 3 & 2 & 10 \\
\hline
\end{tabular}

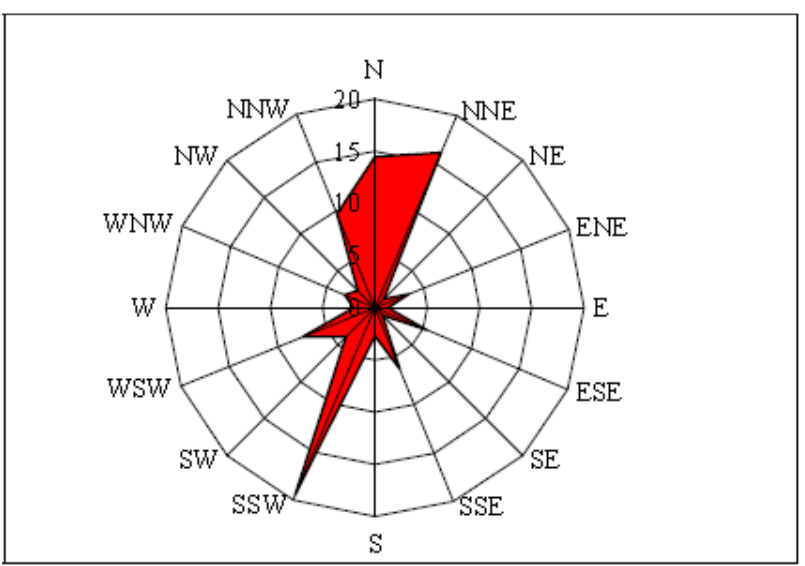

Figure 3. Annual wind rose of the marine area, [1].

The primary wind conditions that generate waves, which are used as input to SEDTRANS, are provided in Table 2. Winds from the SW to the NE come off the land and winds from ENE and E have a short fetch and are not common.

Table 2. Wind conditions in SEDTRANS model.

\begin{tabular}{llll}
\hline Direction & \% Frequency & Total Sec/Year & Comment \\
\hline SE & 6 & 1892160 & Includes SE, ESE \\
SSE & 8 & 2522880 & Includes SSE, S \\
SSW & 23 & 7253280 & Includes SSW, SW \\
Total & 37 & 11668320 & \\
\hline
\end{tabular}

\subsection{Wave Climate}

The probability distribution for waves based on wind conditions and fetch is considered as sample data, [2], and then probabilistic wave heights, periods and directions are developed. The principal wave components, which are used in the sediment transport model, are identified and presented in Table 3.

Table 3. Wave Frequency analysis and values used in SEDTRANS model.

\begin{tabular}{llll}
\hline Frequency & Total sec(Table 2) & $\mathbf{H}_{\mathbf{O}}(\mathbf{m})$ & T (sec) \\
\hline Wind Direction: SE & & & \\
$84.39 \%$ & 1596715 & 0.50 & 2.67 \\
$13.18 \%$ & 249314 & 1.00 & 3.77 \\
$2.44 \%$ & 46104 & 2.00 & 5.34 \\
$0.0014 \%$ & 27 & 4.00 & 7.55 \\
$100.00 \%$ & 1892160 & & \\
Wind Direction: SSE & & & \\
$86.42 \%$ & 2180312 & 0.50 & 2.67 \\
$11.73 \%$ & 296056 & 1.00 & 3.77 \\
$1.84 \%$ & 46499 & 2.00 & 5.34 \\
$0.0005 \%$ & 13 & 4.00 & 7.55 \\
$100.00 \%$ & 2522880 & & \\
Wind Direction: SSW & & & \\
$53.02 \%$ & 3846017 & 0.50 & 2.67 \\
$24.92 \%$ & 1807758 & 1.00 & 3.77 \\
$21.03 \%$ & 1525064 & 2.00 & 5.34 \\
$1.0263 \%$ & 74440 & 4.00 & 7.55 \\
$100.00 \%$ & 7253280 & & \\
\hline & & &
\end{tabular}




\subsection{Shoreline Types, Grain Size and Bathymetry}

Shorelines in the area were categorized during recent field surveys. The primary shorelines with the estimated average grain size and porosity of each category are listed in Table 4.

Table 4. Sediment types with K and grain size parameters used in SEDTRANS.

\begin{tabular}{lll}
\hline Shoreline Type & K & Grain Size $\left.\left(\mathbf{d}_{\mathbf{0}}\right) \mathbf{( m m}\right)$ \\
\hline Fine-Medium Sand & .039 & 0.25 \\
Mixed Sand and Gravel & 0.03 & 2.0 \\
Gravel & 0.01 & 20 \\
Boulder / Riprap & 0 & 1000 \\
\hline
\end{tabular}

Bathymetry was digitized from a nautical chart. In the area of the new coastal structure, bathymetry was also updated. A map of shoreline types and bathymetry is presented in Figure 4.
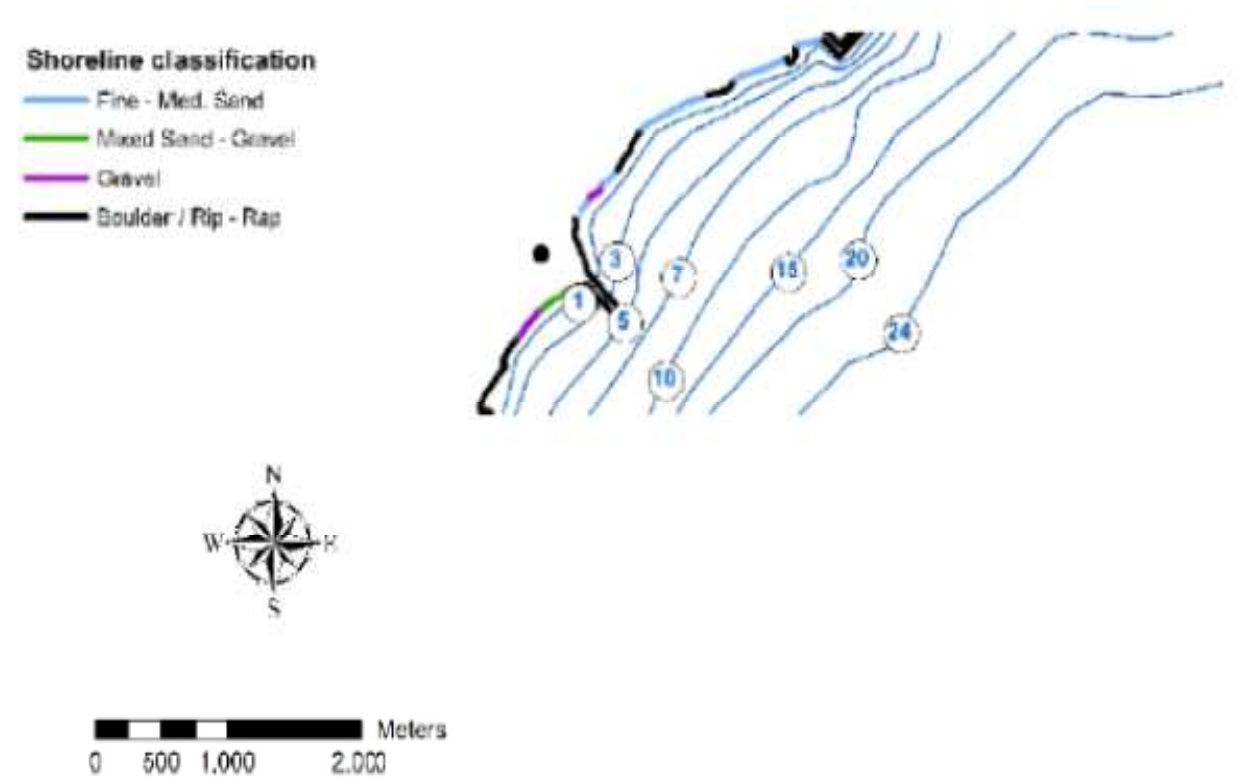

Figure 4. Bathymetry and shoreline types in the marine area, [1].

\subsection{The SEDTRANS Model}

The SEDTRANS model has features of, [2-15]:

Refraction: Refraction is the bending of waves because of varying water depths on the water bottom, bathymetry. The part of a wave in shallow water moves slower than the part of a wave in deeper water. So, when the depth under a wave crest varies along the wave crest, the wave bends, according to Snell's Law. An example of refraction is when waves approach a straight shoreline at an angle.

Diffraction: Diffraction usually happens when waves encounter an obstacle, such as a breakwater, marine structure or an island. The turning of the waves into the sheltered region results the changes in wave heights in the waves and waves spread out. A parameterization technique was developed for diffraction in the SEDTRANS.

Transport rate or erosion and deposition, $Q_{l}$, from CEM 1998, [2], is;

$Q_{1}=K\left[\frac{\rho \sqrt{g}}{16 \kappa^{1 / 2}\left(\rho_{s}-\rho\right)(1-n)}\right] H_{b}^{5 / 2} \sin \left(2 \alpha_{b}\right)(1)$

where ; $\rho_{\mathrm{s}}=$ the mass density of the sediment grains $\left(\rho_{\mathrm{s}}=2650 \mathrm{~kg} / \mathrm{m}^{3}\right)$;

$\rho=$ the mass density of water $\left(\rho=1025 \mathrm{~kg} / \mathrm{m}^{3}\right)$;

$\mathrm{n}=$ in place sediment porosity $(\mathrm{n} \cong 0.4)$;

$\mathrm{K}=$ dimensionless coefficient (see Table 4 );

$\kappa=$ the breaker index $(=0.72+5.6 S)$;

$\mathrm{S}=$ the bottom slope;

$\alpha_{b}=$ the breaker angle relative to the shoreline;

$\mathrm{H}_{\mathrm{b}}=$ breaking wave height;

$$
H_{b}=H_{I}^{4 / 5}\left(\frac{c_{g l} \cos \alpha_{I}}{\sqrt{g / \kappa} \cos \alpha_{b}}\right)^{2 / 5}
$$

$c_{g l}=$ the deep water wave celerity $(=g T / 2 \pi)$;

$\mathrm{T}=$ the wave period;

$\alpha_{I}=$ the deep water wave direction; and

$\mathrm{H}_{\mathrm{I}}=$ deep water wave height.

SEDTRAN calculates shore-reaching angle, transport with given conditions.

\section{Results}




\subsection{SE Wave Conditions (Before and After Jetty)}

A jetty, which new installation on the shore line, is constructed in the shore area, for these conditions, the transport rates and wave rays before and after jetty placement are shown in Table 5.

Table 5. Wave refraction and sediment transport rates for $0.5 \mathrm{~m}, 1.0 \mathrm{~m}, 2.0 \mathrm{~m}$ and $4.0 \mathrm{~m} \mathrm{SE}$ waves, [1].

Before Jetty
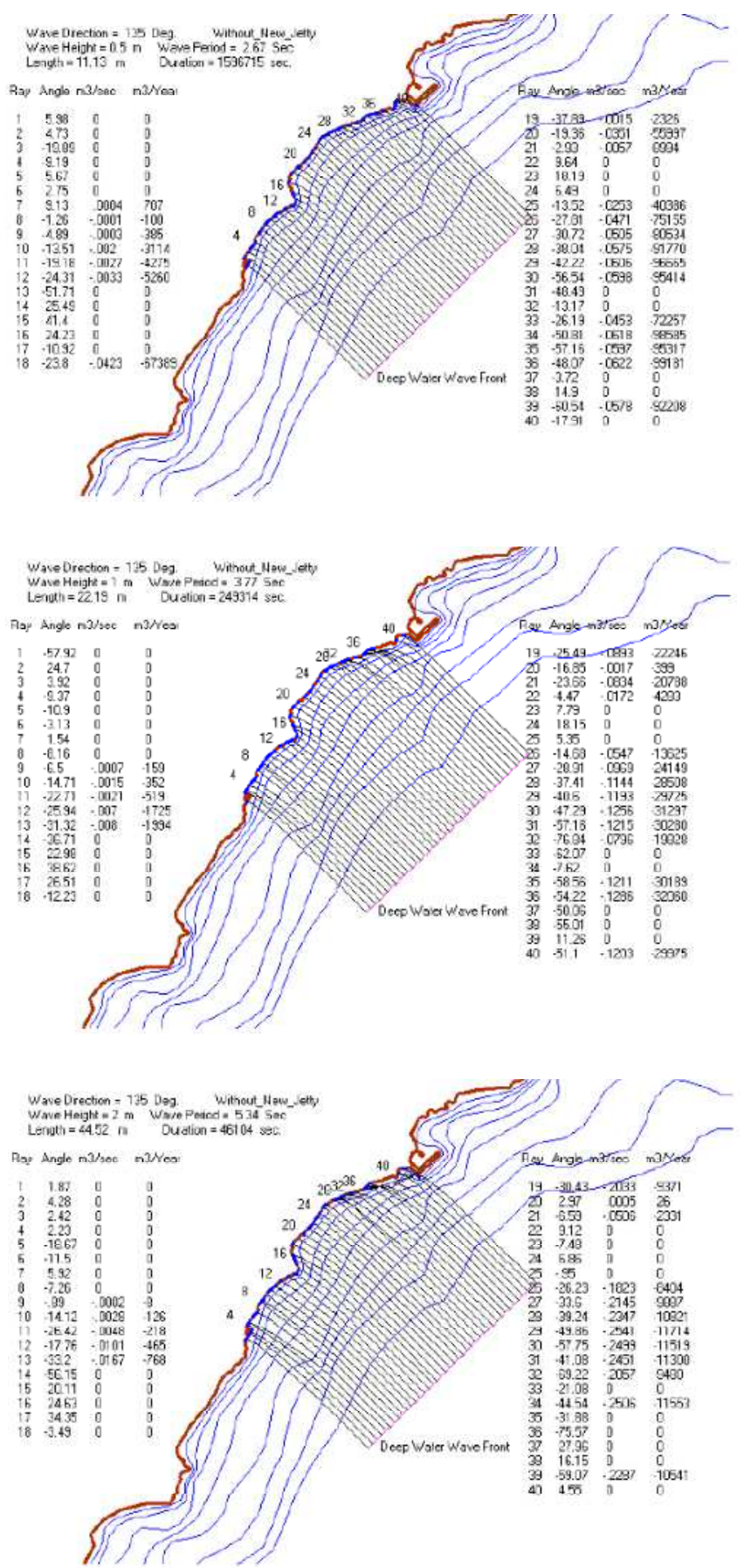

After Jetty
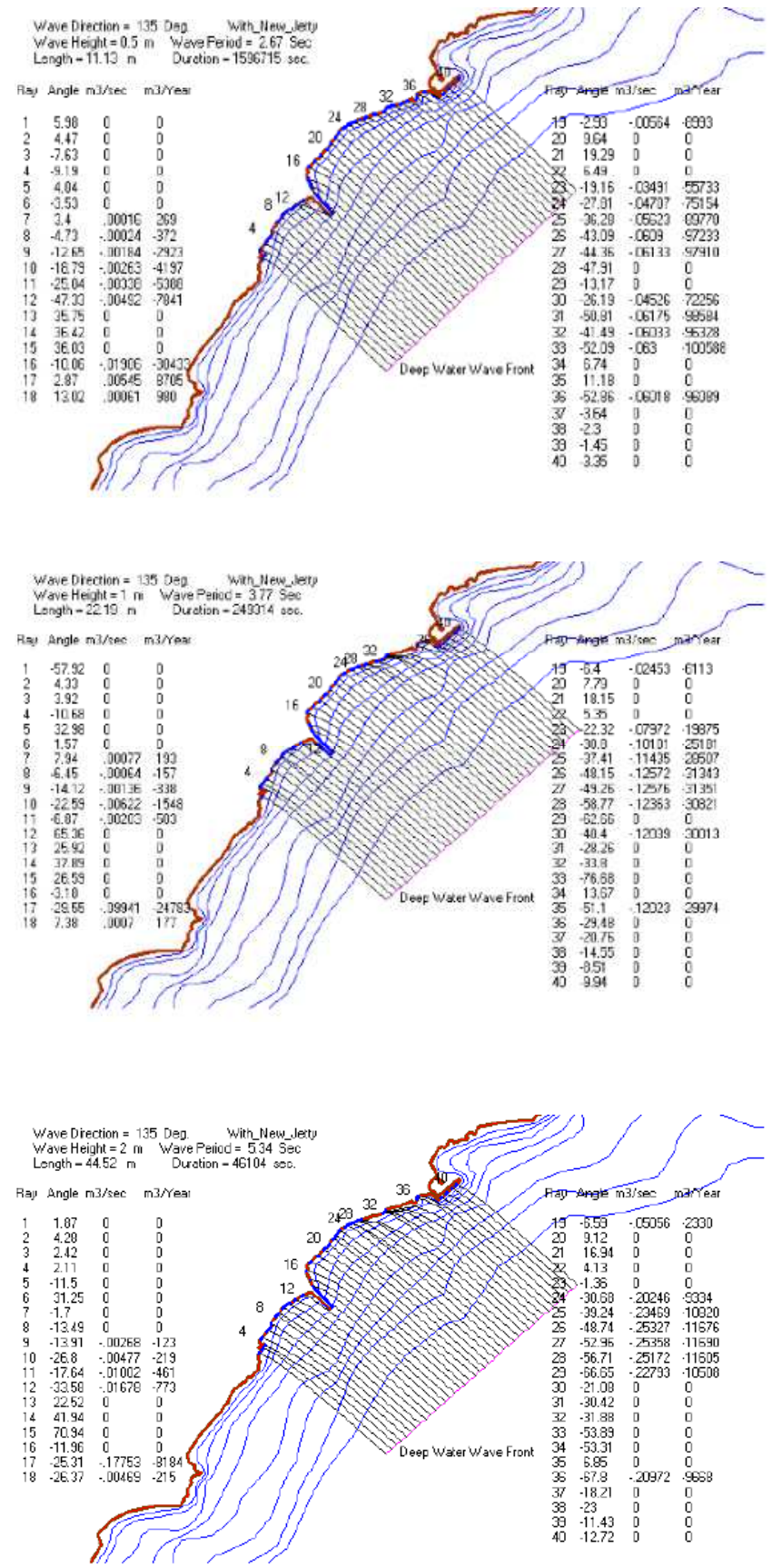
Before Jetty

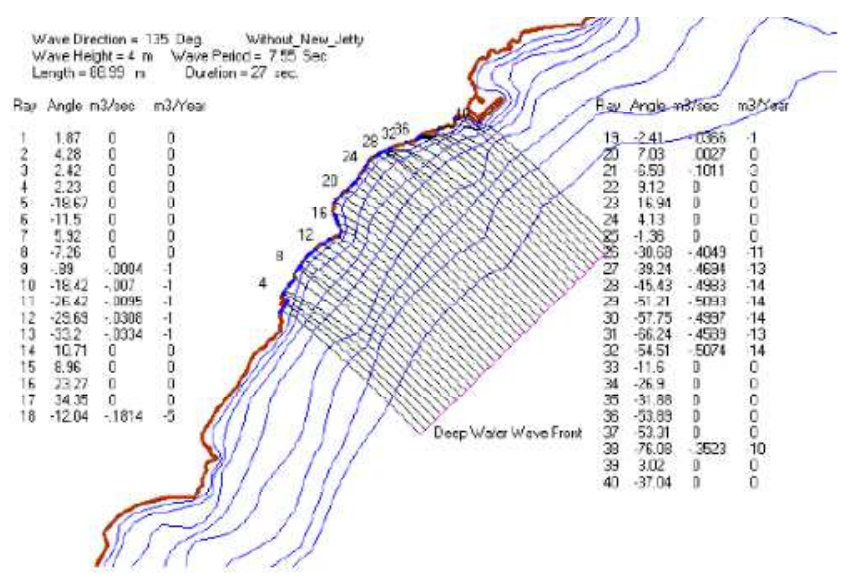

After Jetty

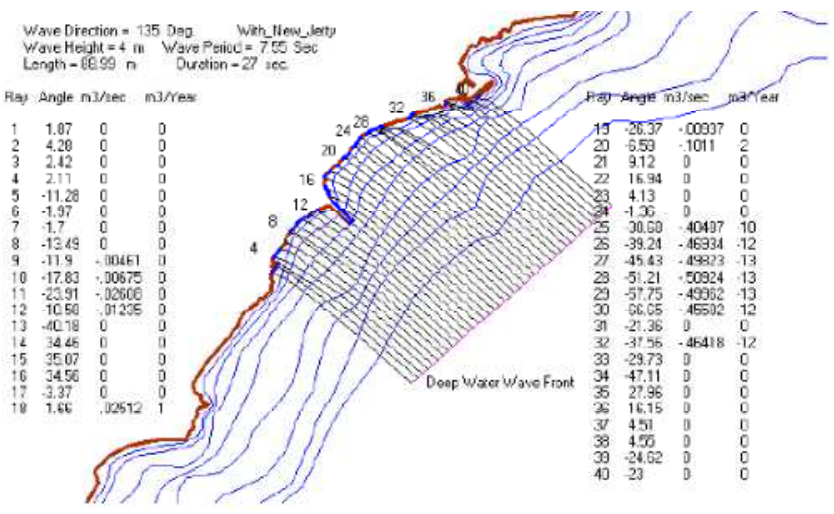

\subsection{SSE Wave Conditions (Before and After Jetty)}

before and after jetty placement are shown in Table 6 .

For these conditions, the transport rates and wave rays

Table 6. Wave refraction and sediment transport rates for $0.5 \mathrm{~m}, 1.0 \mathrm{~m}, 2.0 \mathrm{~m}$ and $4.0 \mathrm{~m}$ SSE waves, [1].

Before Jetty
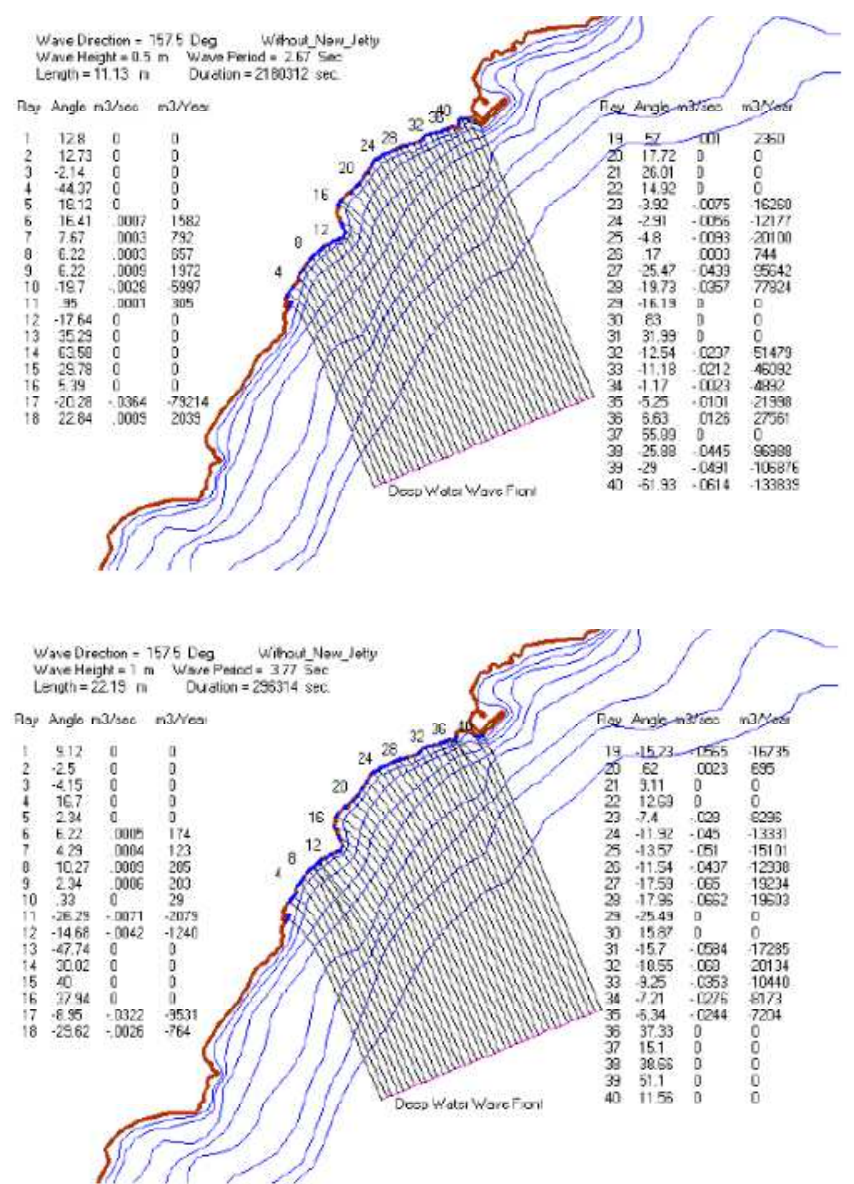

After Jetty
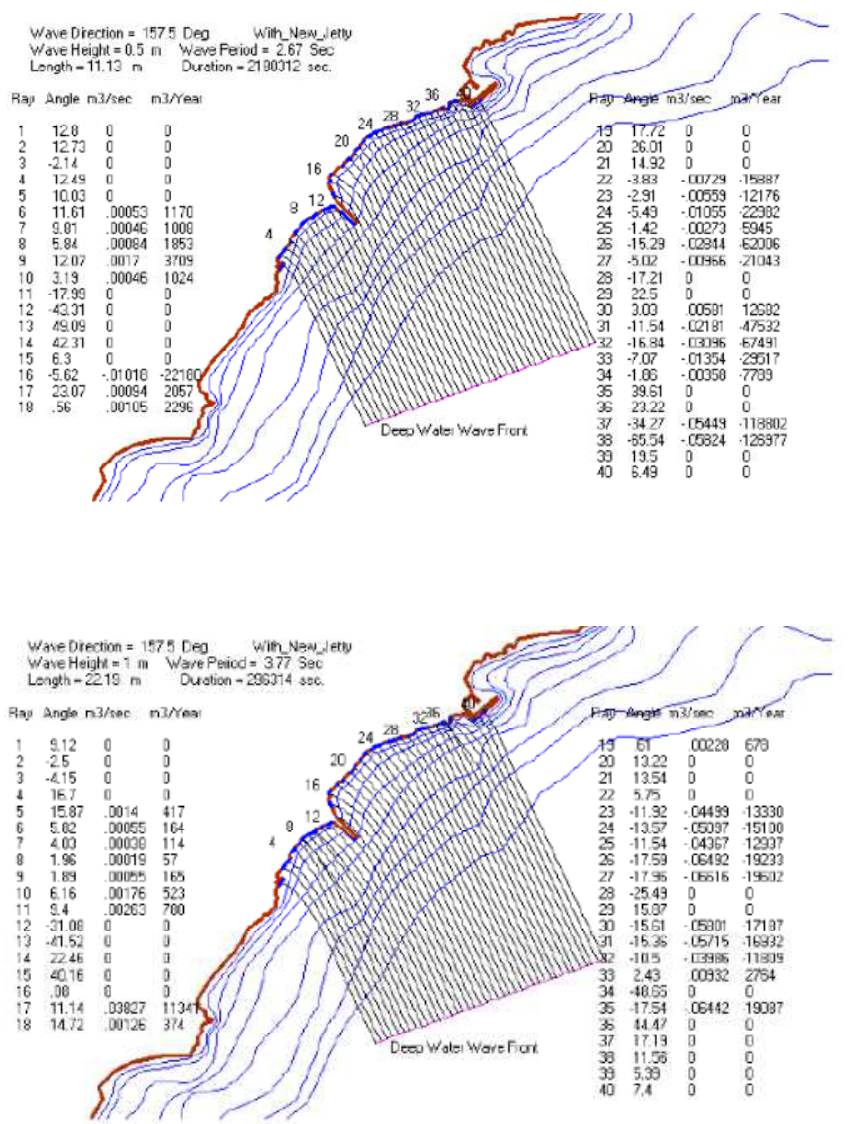
Before Jetty
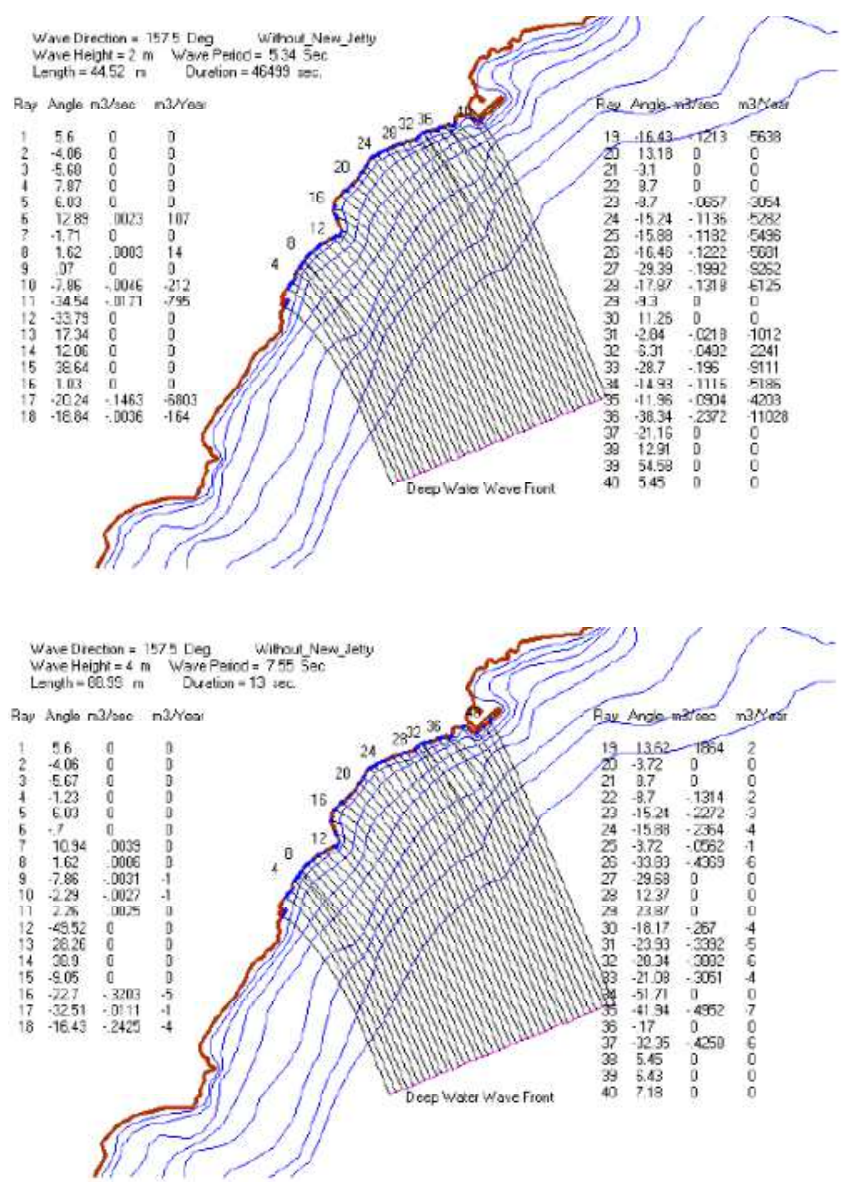

\subsection{SSW Wave Conditions (Before and After Jetty)}

For these conditions, the transport rates and wave rays
After Jetty
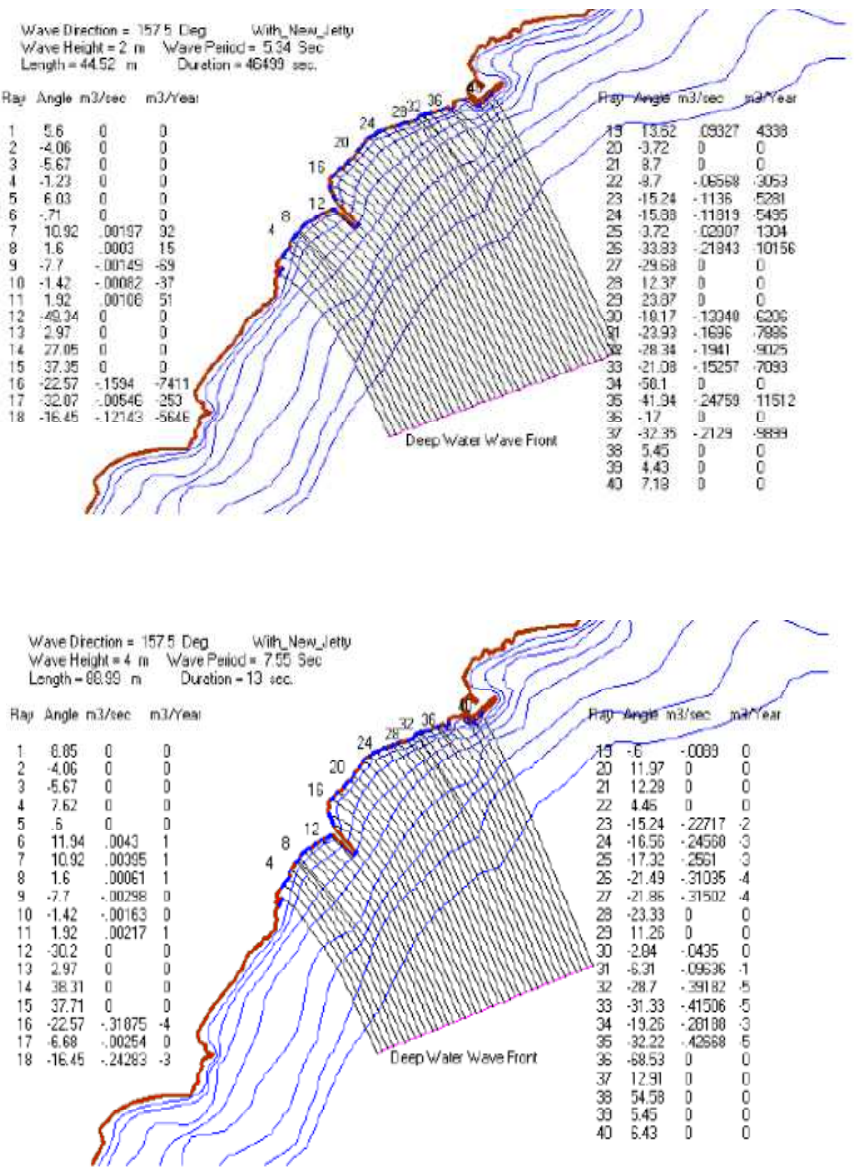

before and after jetty placement are shown in Tables 7 and 8.

Table 7. Wave refraction and sediment transport rates for $0.5 \mathrm{~m}, 1.0 \mathrm{~m}, 2.0 \mathrm{~m}$ and $4.0 \mathrm{~m}$ SSW waves, [1].

Before Jetty

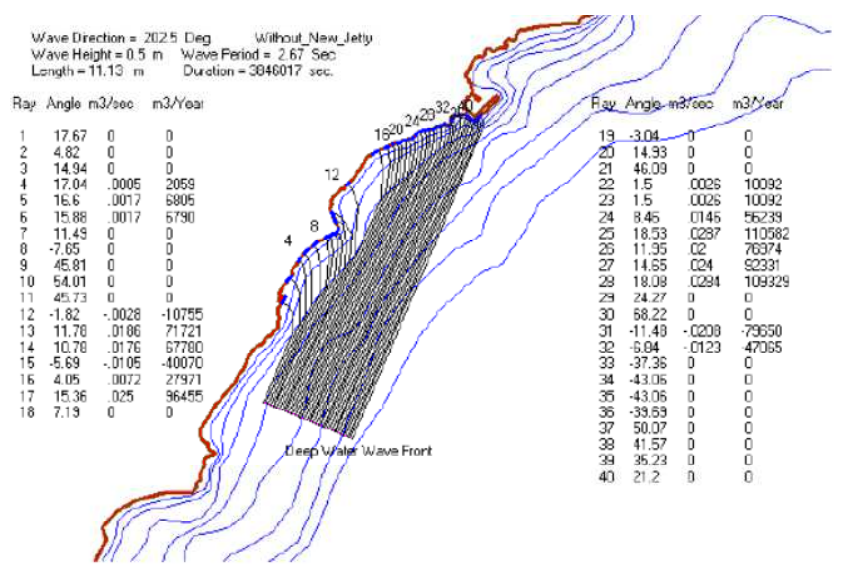

After Jetty

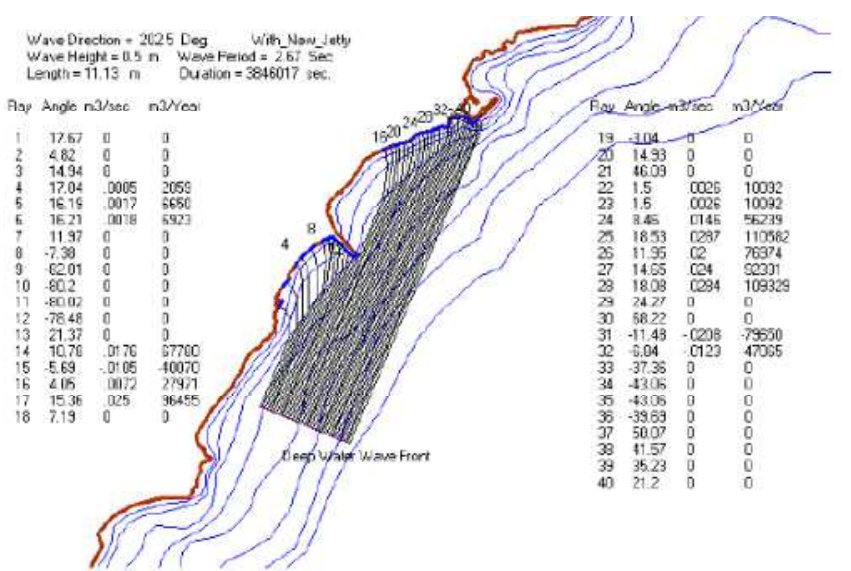


Before Jetty
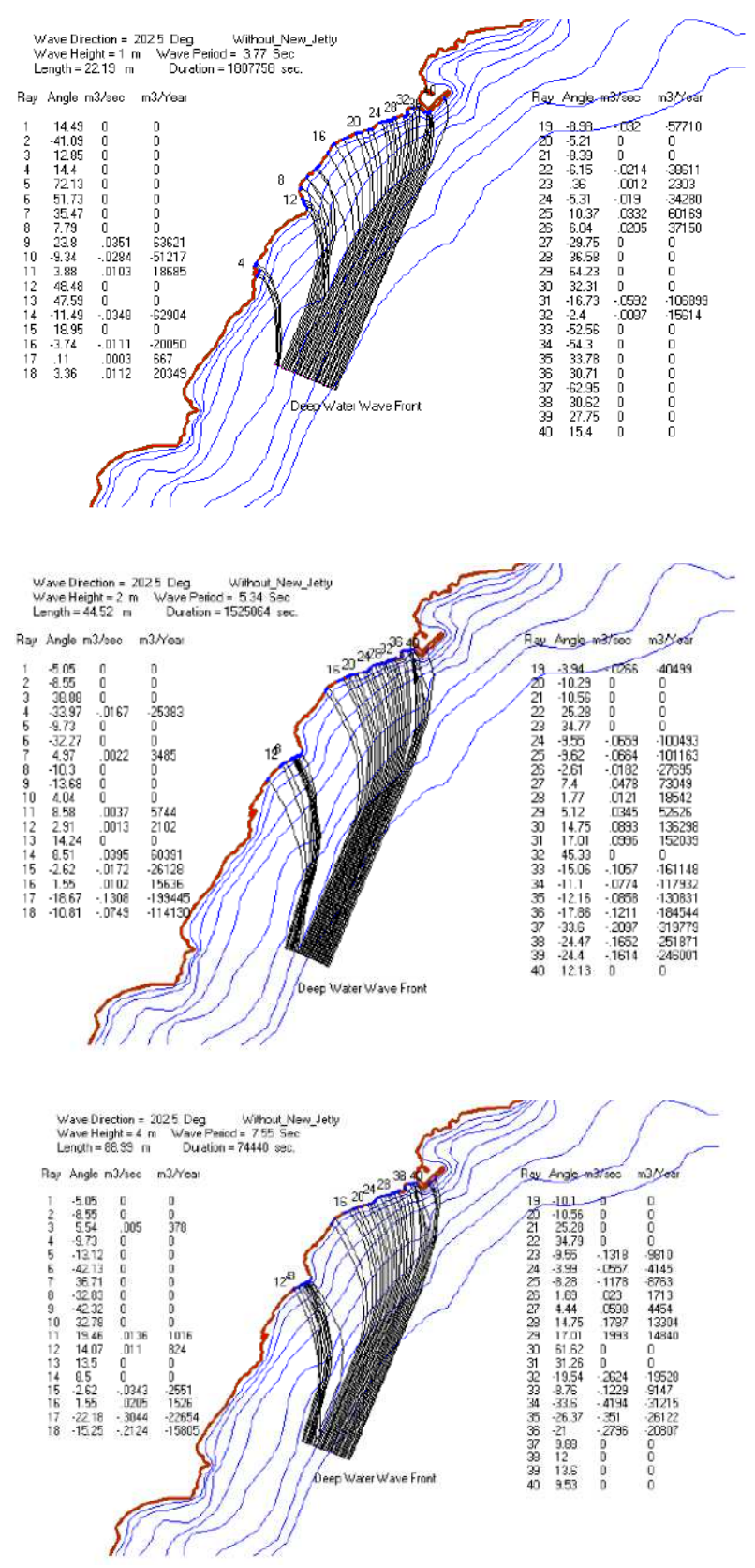

After Jetty
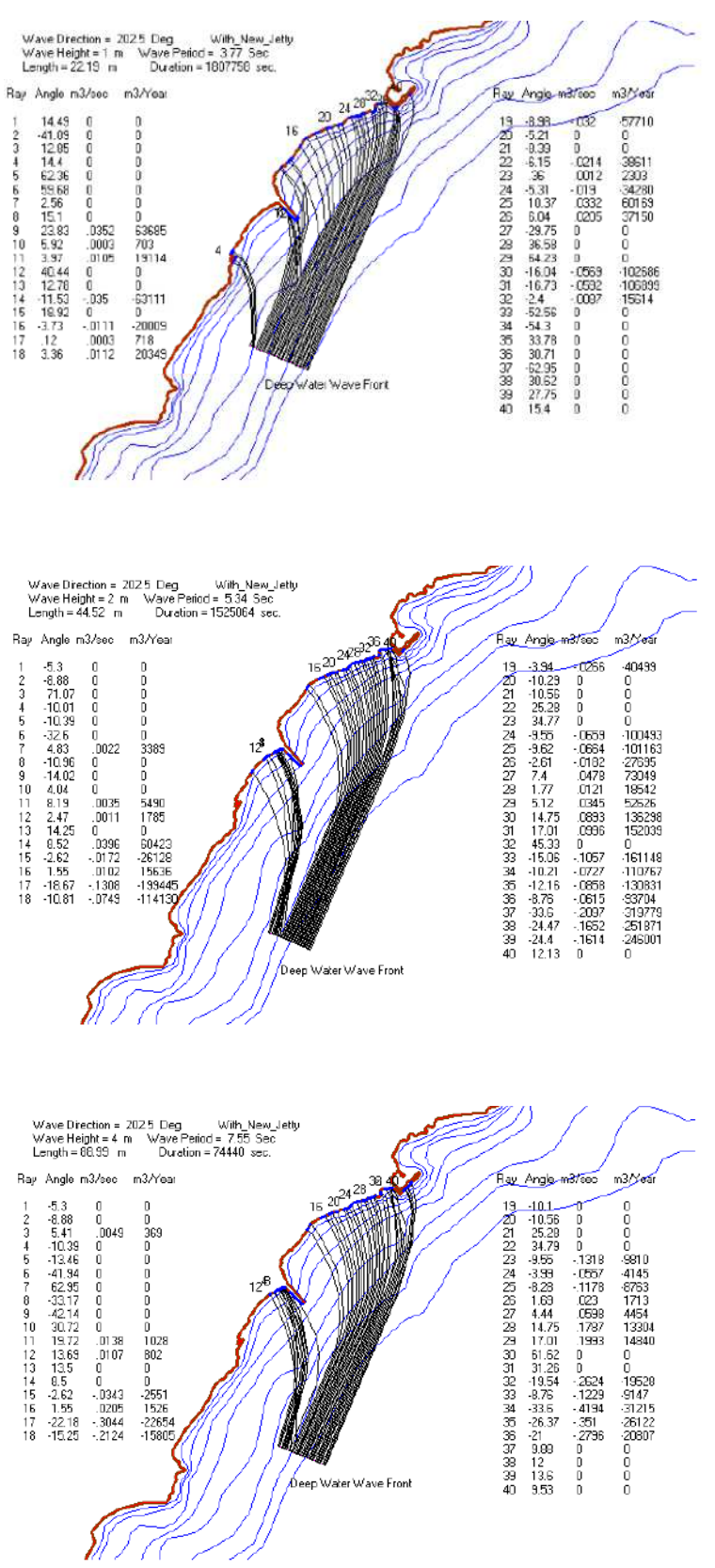

Table 8. Detailed view around new jetty SSW waves, [1].
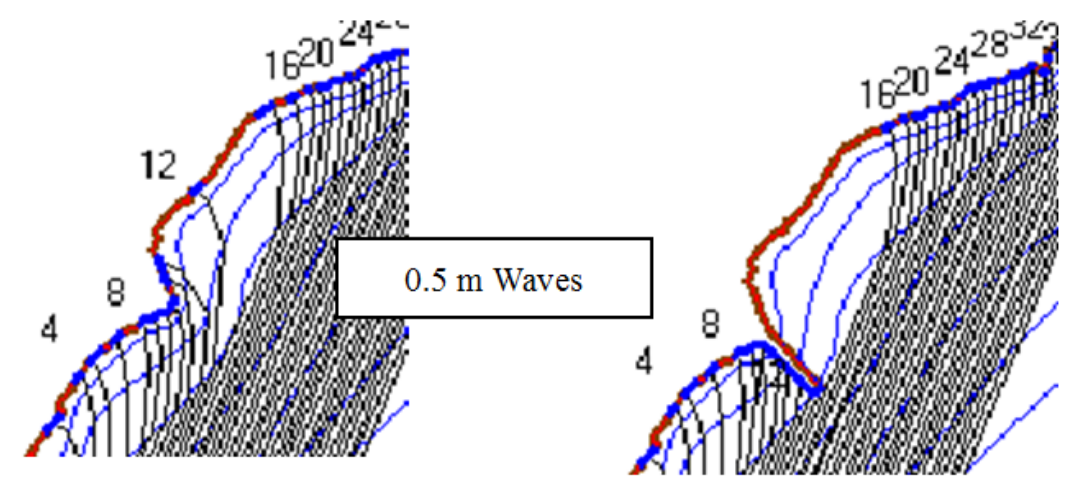

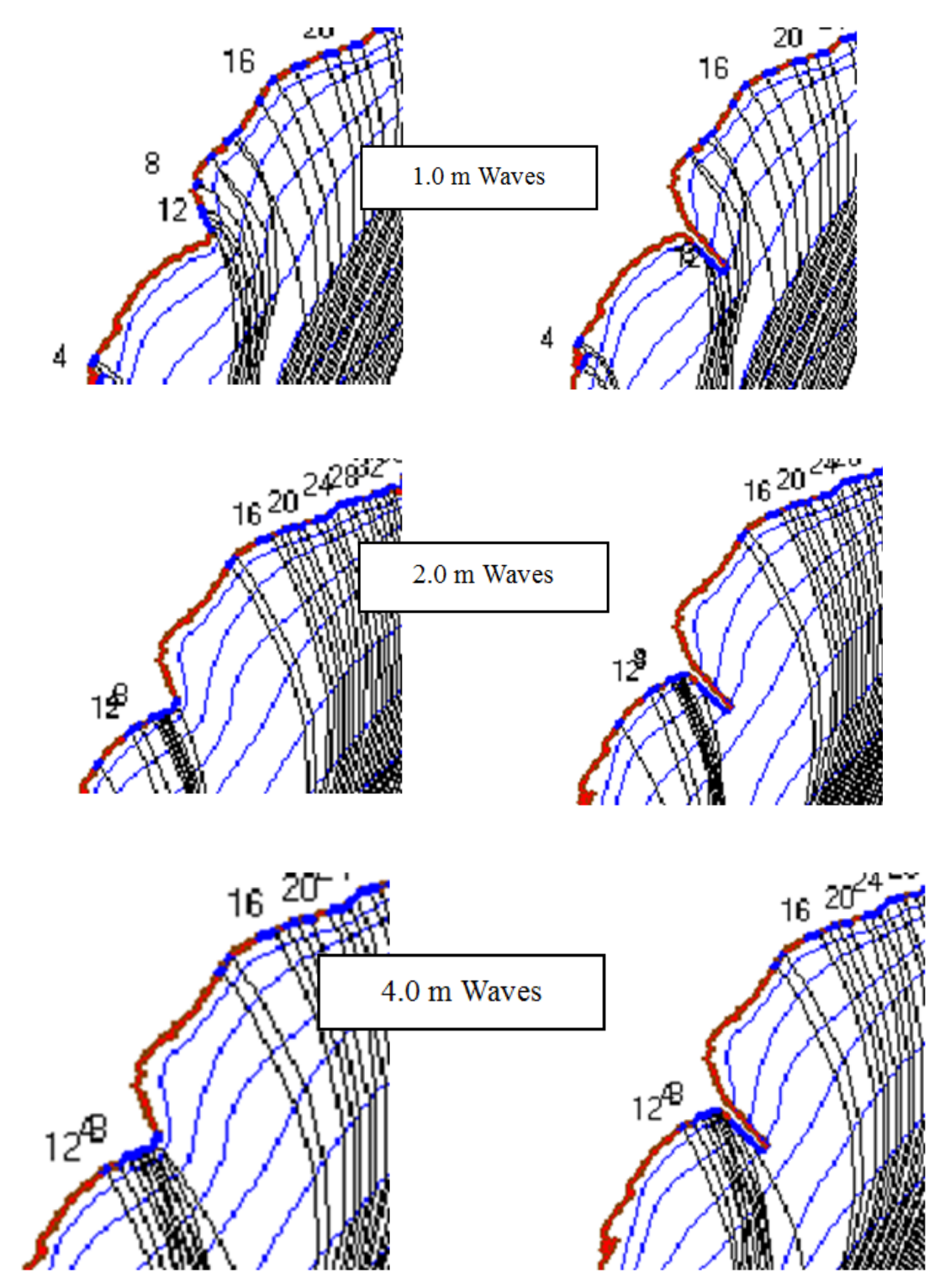

Table 9. Analyse of annual sediment transport at three locations; before and after jetty, [1].

\begin{tabular}{|c|c|c|c|c|c|c|c|c|c|c|c|c|c|}
\hline \multicolumn{2}{|l|}{ Waves } & \multicolumn{4}{|c|}{ South of New Jetty } & \multicolumn{4}{|c|}{ North of New Jetty } & \multicolumn{4}{|c|}{ East of Jetty } \\
\hline Height & Dir & \# & BEFORE & AFTER & \# & \# & BEFORE & AFTER & \# & \# & BEFORE & AFTER & \# \\
\hline 0.5 & 135.0 & 12 & -5260 & -7841 & 12 & 18 & -67389 & -30433 & 16 & 39 & -92208 & -96089 & 36 \\
\hline 1 & & 13 & -1994 & -503 & 11 & 19 & -22246 & -24783 & 17 & 40 & -29975 & -29974 & 35 \\
\hline 2 & & 13 & -768 & -773 & 12 & 19 & -9371 & -8184 & 17 & 39 & -10541 & -9668 & 36 \\
\hline 4 & & 13 & -1 & no strike & 12 & 18 & -5 & 1 & 19 & 38 & -10 & no strike & \\
\hline Subtotal & & & -8023 & -9117 & & & -99011 & -63399 & & & -132734 & -135731 & \\
\hline 0.5 & 157.5 & 11 & 305 & 1024 & 10 & 17 & -79214 & -22180 & 16 & 40 & -133839 & -126977 & 38 \\
\hline 1 & & 12 & -1240 & 780 & 11 & 17 & -9531 & 11341 & 17 & 35 & -7204 & -19087 & 35 \\
\hline 2 & & 11 & -795 & 51 & 11 & 17 & -6803 & -7411 & 16 & 36 & -11028 & -9899 & 37 \\
\hline 4 & & 10 & -1 & no strike & 10 & 16 & -5 & -4 & 16 & 37 & -6 & -5 & 35 \\
\hline Subtotal & & & -1731 & 1855 & & & -95553 & -18254 & & & -152077 & -155968 & \\
\hline 0.5 & 202.5 & 6 & 6790 & 6923 & 6 & 12 & -10755 & no strike & & 32 & -47065 & -47065 & 32 \\
\hline 1 & & & no strike & no strike & 11 & 9 & 63621 & 63685 & 9 & 32 & -15614 & -15614 & 32 \\
\hline 2 & & 7 & 3485 & 1785 & 12 & 14 & 60391 & no strike & & 39 & -246001 & -246001 & 39 \\
\hline 4 & & 12 & 824 & 802 & 12 & 15 & -2551 & no strike & & 36 & -20807 & -20807 & 36 \\
\hline Subtotal & & & 11291 & 9510 & & & 110706 & 63685 & & & -329487 & -329487 & \\
\hline Total & & & 1537 & 2248 & & & -83858 & -17968 & & & -614298 & -621186 & \\
\hline
\end{tabular}

${ }^{\prime}+{ }^{\prime}=$ transport to right of wave ray, ${ }^{\circ} \cdot{ }^{c}=$ transport to left of wave ray.

$' \#$ ' = wave ray number from refraction diagram. 


\section{Discussion of Results}

It is seen that there are no changes in wave rays before and after jetty placement for waves coming from the SSE and SE because of the alignment of the jetty with the approaching waves. SSW waves show some shadowing due to the jetty, which is evident under the $0.5 \mathrm{~m}$ and $1.0 \mathrm{~m}$ waves, however there is also a natural shadowing to the north due to the natural refraction of SSW waves due to bathymetry, as shown under $2.0 \mathrm{~m}$ and $4.0 \mathrm{~m}$ wave conditions (Tables 7 and 8 ).

An analyse of the annual sediment transport rates at three locations, south of the jetty, north of the jetty, and surrounding are presented in Table 9. Results of this analysis indicate:

- No net change east of the jetty,

- No net change south of the jetty.

- Several changes north of the jetty:

- Less transport southward with waves from SE and SSE.

- Less northward transport with SSW waves due to shadow zone.

- Less annual transport to the south.

In detail analysis, these conclusions are not altered significantly by analyzing the shoreline with the jetty and surrounding by using the SEDTRANS model. In other words, there are no significant expected changes in annual sedimentary transport along shorelines adjacent to the new jetty, see Table 9. The transport north of the jetty has decreased because this area is being sheltered by the jetty. However, annual sedimentary transport has not been changed, and the shorelines are expected to remain stable with the jetty and surrounding.

\section{References}

[1] H. M. Cekirge, Sediment Transport on Shorelines, Maltepe Uni., Int. Rep. 4, Istanbul, 2010.

[2] CEM, Coastal Engineering Manual, Department of the Army, Corps of Engineers Washington, DC, 1998.

[3] W. Bascom, W. Waves and beaches: the dynamics of the ocean surface. Garden City, NY: Doubleday \& Co., Inc., 1964.
[4] P. Komar, Beach processes and sedimentation. Englewood Cliffs, NJ: Prentice-Hall, Inc., 1976.

[5] G. Dean and R.A. Dalrymple, Water wave mechanics for engineers and scientists. Singapore: World Scientific, 1991.

[6] M. B. Abbott, H. M. Petersen, and O. Skovgaard, On the Numerical Modelling of Short Waves in Shallow Water, Journal of Hydraulic Research 16, 3, 173-203, 1978.

[7] Earl J. Hayter, John M. Hamrick, Brian R. Bicknell, and Mark H. Gray, One-Dimensional Hydrodynamic/Sediment, Transport Model for Stream Networks, EPA/600/R-01/072, September 2001

[8] L. O. Amoudry and A. J. Souza (2011), Impact of sediment - induced stratification and turbulence closures on sediment transport and morphological modelling, Cont. Shelf Res., 31, 912-928, 2011.

[9] M. Blaas, C. Dong, P. Marchesiello, J. C. McWilliams, and K. D. Stolzenbach (2007), Sediment - transport modeling on Southern Californian shelves: A ROMS case study, Cont. Shelf Res., 27, 832-853, 2007.

[10] A. F. Blumberg, A Primer for ECOMSED, Version 1.3, users manual, HydroQual, Inc., Mahwah, N. J, 2002

[11] H. J. de Vriend, 2D mathematical modelling of morphological evolutions in shallow water, Coastal Eng., 11, 1-27. 1987.

[12] H. J. de Vriend, and J. S. Ribberink, A quasi - 3D mathematical model of coastal morphology, in Proceedings of the 21st International Conference on Coastal Engineering, edited by B. L. Edge, pp. 1689-1703, Am. Soc. of Civ. Eng., Reston, Va., 1988.

[13] US Army Corps of Engineer, Predicting Deposition Patterns in Small Basins, TP-133, March 1991.

[14] Yu-Min Wang, Jan-Mou Leu, Seydou Traore, Chou-Ping Yang, Lian-Tsai Deng and Tso-Hsin Weng, Apprehending the potential effect of sediment deposition due to dredging in Laonong River upstream, Southern Taiwan, International Journal of the Physical Sciences Vol. 5(14), pp. 2135-2142, 4 November, 2010.

[15] Edited by Wolfgang Summer and Desmond E. Walling, Modelling Erosion, Sediment Transport and Sediment Yield, A contribution to IHP-V Projects 2.1 and 6.2, International Hydrological Programme, I HP-VI, Technical Documents in Hydrology, No. 60 UNESCO, Paris, 2002. 